\title{
Heteroepitaxial growth of SiC films by carbonization of polyimide Langmuir-Blodgett films on $\mathrm{Si}$
}

\author{
S.I. Goloudina ${ }^{1, *}$, V.V. Luchinin ${ }^{1}$, V.M. Pasyuta ${ }^{1}$, M.F. Panov ${ }^{1}$, A.N. Smirnov ${ }^{2}$, D.A. Kirilenko², \\ T.F. Semenova ${ }^{3}$,V.P. Sklizkova ${ }^{4}$, I.V. Gofman ${ }^{4}$, V.M. Svetlychnyi ${ }^{4}$ and V.V. Kudryavtsev ${ }^{4}$ \\ ${ }^{1}$ St. Petersburg State Electrotechnical University, 197376, 5 Prof. Popov st., St. Petersburg, Russia \\ ${ }^{2}$ Ioffe Institute, RAS, 194021, 26 Politekhnicheskaya, St Petersburg, Russia \\ ${ }^{3}$ St. Petersburg State University, 199034, 7-9 Universitetskaya nab., St. Petersburg, Russia \\ ${ }^{4}$ Institute of Macromolecular Compounds, 199004, 31 RAS, Bol'shoy pr., St.Petersburg, Russia
}

\begin{abstract}
High quality single crystal $\mathrm{SiC}$ films were prepared by carbonization of polyimide Langmuir-Blodgett films on Si substrate. The films formed after annealing of the polyimide films at $1000^{\circ} \mathrm{C}, 1100^{\circ} \mathrm{C}, 1200^{\circ} \mathrm{C}$ were studied by Fourier transform-infrared (FTIR) spectroscopy, X-ray diffraction (XRD), Raman spectroscopy, transmission electon microscopy (TEM), transmission electron diffraction (TED), and scanning electron microscopy (SEM). XRD study and HRTEM crosssection revealed that the crystalline $\mathrm{SiC}$ film begins to grow on $\mathrm{Si}(111)$ substrate at $1000^{\circ} \mathrm{C}$. According to the HRTEM cross-section image five planes in 3C-SiC (111) film are aligned with four $\mathrm{Si}(111)$ planes at the $\mathrm{SiC} / \mathrm{Si}$ interface. It was shown the $\mathrm{SiC}$ films $(35 \mathrm{~nm})$ grown on $\mathrm{Si}(111)$ at $1200^{\circ} \mathrm{C}$ have mainly cubic $3 \mathrm{C}$-SiC structure with a little presence of hexagonal polytypes. Only $3 \mathrm{C}$ $\mathrm{SiC}$ films $(30 \mathrm{~nm})$ were formed on $\mathrm{Si}(100)$ substrate at the same temperature. It was shown the $\mathrm{SiC}$ films (30-35 nm) are able to cover the voids in Si substrate with size up to $10 \mu \mathrm{m}$.
\end{abstract}

\section{Introduction}

Among various semiconductor materials, silicon carbide $(\mathrm{SiC})$ is an attractive material for high power, high frequency and high temperature microelectronics, owing in part to its wide band gap, high thermal conductivity, high break down field and high saturation velocity. Compared with $\mathrm{Si}$ or GaAs, it is chemically inert, extremely hard, radiation-resistant, and highly wear-resistant making it possible to fabricate microsensors and microactuators for harsh environments such as high temperature, aggressive media, and radiation-exposed environments. Additionally, $\mathrm{SiC}$ is inert to most chemicals at room temperature and has been found to be biocompatible with inert to bacterial growth, transparent to visible light, and show UV wavelength absorption. Furthermore, owing to its large ratio of Young's modulus to density, $\mathrm{SiC}$ has also attractive interest for use in ultra-high-frequency nanoelectromechanical system (NEMS) for wire-less signal-processing systems. However, this material has not been widely used because of the difficulties in growing high quality crystals and etching the material to form required pattern.
The motivation for the heteroepitaxial growth of SiCon-Si has been to provide relatively inexpensive and large-area substrates of $\mathrm{SiC}$ for electronic devices and microelectromechanical system. Due to its large energy band and other promising semiconductor properties, 3C$\mathrm{SiC}$ has potential for high performance as a wide bandgap emitter to the $\mathrm{SiC} / \mathrm{Si}$ heterojunction bipolar transistor. Also SiC film on Si can be used as a buffer layer for the subsequent heteroepitaxial growth of gallium nitride and other group III-nitrides, which has application in blue and violet light-emitting diodes and lasers. However, the growth of $\mathrm{SiC}$ films on $\mathrm{Si}$ is one of the most difficult challenges of heteroepitaxy due to the large mismatches in lattice constant $(20 \%)$ between $\mathrm{SiC}$ and $\mathrm{Si}$, and the difference in the thermal expansion coefficient of $\mathrm{SiC}$ $\left(4.6 \times 10^{-6} /{ }^{\circ} \mathrm{C}\right)$ and $\mathrm{Si}\left(4.2 \times 10^{-6} /{ }^{\circ} \mathrm{C}\right)$. The usual techniques to grow $\mathrm{SiC}$-on-Si are chemical vapor deposition (CVD), laser sputtering, molecular beam epitaxy, and carbonization of a polyimide Langmuir-Blodgett (LB) film on silicon substrate. Currently, the high quality crystalline $\mathrm{SiC}$ films on $\mathrm{Si}$ can be fabricated by CVD method $[1,2]$, thickness of such films is often more than several microns. If the films thickness is less than one

\footnotetext{
* Corresponding author: goloudina@mail.ru
} 
micron, it usually contains a large number of defects $[3$, 4].

The aim of this work was to prepare $\mathrm{SiC}$ films on $\mathrm{Si}$ by carbonization of rigid-rod polyimide (BPDA-oTD) LB films and studying their structure and morphology.

\section{Materials and Methods}

As polyimide prepolymer, we used polyamic acid alkylammonium salt (PAAS) synthesized on the basis of 3,3',4,4'-diphenyltetracarboxylic acid dianhydride and otolidine with tert-amine o,o',o"trihexadecanoyltriethanolamine. The PAAS forms wellordered and stable monolayers at the air-water interface. The PAAS monolayers were deposited on the silicon support at the surface pressure $30 \mathrm{mN} / \mathrm{m}$. Y-type of deposition was observed. The transfer rate was 0.5 $\mathrm{cm} / \mathrm{min}$. [5].

PAAS LB films of 81, 121, 141 layers were deposited on $\mathrm{Si}(11)$ and $\mathrm{Si}(100)$ substrates. The polyimide (PI) films were then formed by thermal imidization of PAAS LB films (figure 1). The PI films had thickness of 47, 54 and $86 \mathrm{~nm}$, respectively.

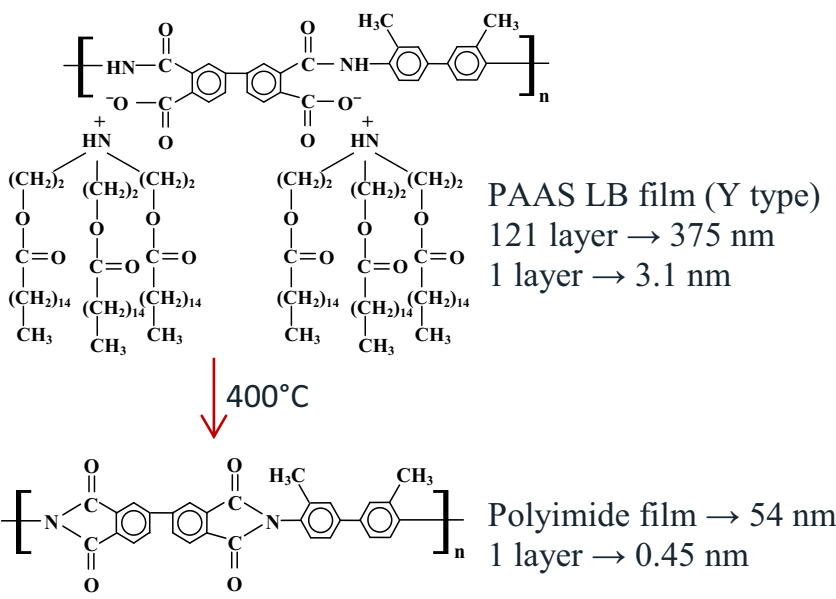

Fig. 1. The scheme of obtaining polyimide film.

For forming $\mathrm{SiC}$ the PI films on Si were annealed by two steps. Firstly the samples were heated to the temperature of $1000^{\circ} \mathrm{C}$ with the velocity of 10 degrees/min. and kept at this temperature during $1 \mathrm{~h}$. After cooling down the samples were studied and then the films were heated again by the quick thermal heat annealing during $3 \mathrm{~min}$. at the temperatures of $1100^{\circ} \mathrm{C}$ or $1200^{\circ} \mathrm{C}$. The annealing was carried out in a vacuum $\left(10^{-}\right.$ ${ }^{5} \mathrm{~mm}$. of m.c.). The films formed after annealing were studied by Fourier transform-infrared (FTIR) spectroscopy, X-ray diffraction (XRD), Raman spectroscopy, high-resolution transmission electron microscopy (HRTEM), transmission electron diffraction (TED), and scanning electron microscopy (SEM).

The transmission spectrums of $\mathrm{SiC}$ films were obtained by using a Nicolet 6700 FT-IR Spectrometer. Raman spectra were acquired by using a Horiba Jobin Yvon T64000 micro-Raman system with a confocal microscope. The samples were excited by a continuous wave diode pumped Nd:YAG $\left(\lambda_{\mathrm{ex}}=532 \mathrm{~nm}\right)$ laser. Raman spectra were measured at room temperature, with the spot size on the sample of about $1 \mu \mathrm{m}$. The excitation power was limited to $1 \mathrm{~mW}$ to avoid sample heating. A standard $\mathrm{Si}(111)$ wafer was used for calibration of the microRaman system. X-ray investigations were carried out on a diffractometer with a Rigaku Ultima IV (CuK $\alpha$ radiation). TEM studies were performed by using a Jeol JEM-2100F transmission electron microscope (accelerating voltage $200 \mathrm{kV}$, point-to-point resolution $0.19 \mathrm{~nm}$ ) equipped with an energy-dispersive X-ray spectrometer Oxford Instruments INCA. High resolution images were obtained in conventional bright-field mode using objective aperture of the optimal size. Specimens for TEM were prepared by mechanical polishing with subsequent ion milling using $\mathrm{Ar}^{+}$at $4 \mathrm{kV}$. The surface morphology of $\mathrm{SiC}$ was examined by FEI Quanta Inspect SEM.

\section{Results and Discussion}

The infrared spectrum of the films after annealing at $1000^{\circ} \mathrm{C}$ is shown in figure 2 . This spectrum was obtained at a "reflection" regime. Only one absorption peak is seen at $796 \mathrm{~cm}^{-1}$, which indicate the TO phonon of the $3 \mathrm{C}-\mathrm{SiC}$ phase.

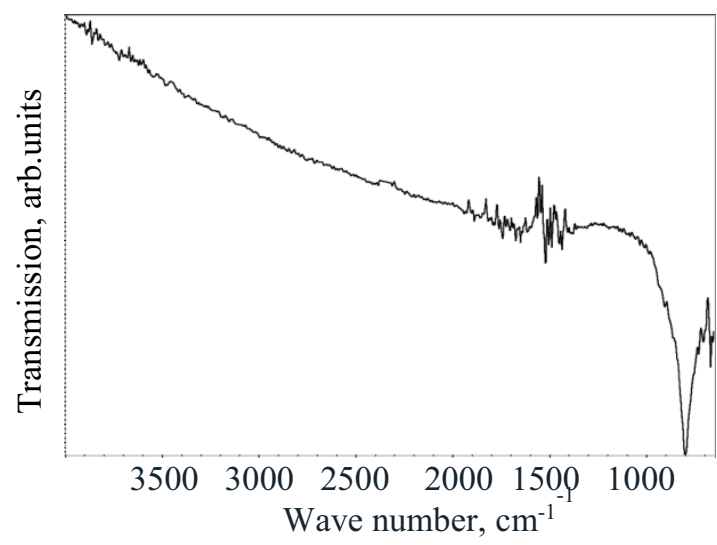

Fig. 2. FTIR spectrum of $\mathrm{SiC}$ films

The interesting details of $\mathrm{SiC}$ formation on $\mathrm{Si}$ were found by Raman spectroscopy. The results show that after heat treatment at $1000^{\circ} \mathrm{C}$ the films on Si consist mainly of amorphous carbon (figure $3 \mathrm{a}$ ). After annealing at $1100^{\circ} \mathrm{C}$ the films contain both the carbon and $\mathrm{SiC}$ phases (figure 3b). Mainly the $\mathrm{SiC}$ phase was formed at $1200^{\circ} \mathrm{C}$ (figure $3 \mathrm{c}, \mathrm{d}$ ).

At the same time, the cross section TEM image of the film formed at $1000^{\circ} \mathrm{C}$ shows the presence of $\mathrm{SiC}$ nanocrystals on the Si surface (figure 4). Furthermore, it is clearly seen that five planes in $3 \mathrm{C}-\mathrm{SiC}(111)$ structure are aligned with four $\mathrm{Si}$ (111) planes at the $\mathrm{SiC} / \mathrm{Si}$ interface.

Formation of high quality $\mathrm{SiC}$ crystalline phase at $1000^{\circ} \mathrm{C}$ was confirmed by X-ray diffraction (figure 5). The peak 1 on the XRD spectrum corresponds to $3 \mathrm{C}$ $\mathrm{SiC}(111)$ structure or H-SiC (table 1). The FWHM of this peak is $0.060^{\circ}$ which indicates the single crystal $\mathrm{SiC}$ phase formation on $\mathrm{Si}$ [1]. 


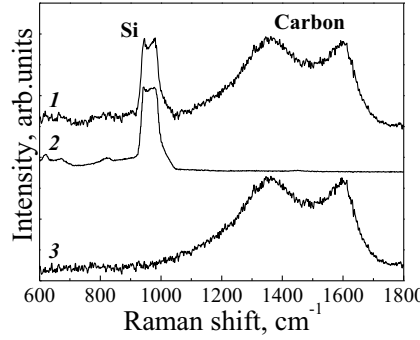

a

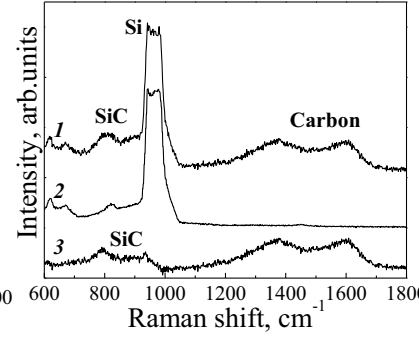

b

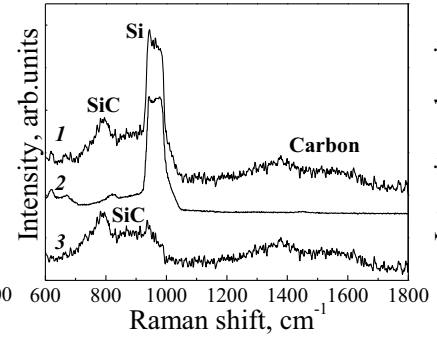

c

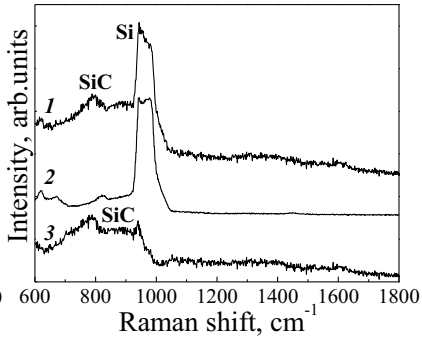

d

Fig. 3. Raman spectra of films formed on $\mathrm{Si}$ substrate at various temperature: $\mathrm{Si}(111)-1000^{\circ} \mathrm{C}(\mathrm{a}), 1100^{\circ} \mathrm{C}(\mathrm{b}), 1200^{\circ} \mathrm{C}(\mathrm{c})$; $\mathrm{Si}(100)-1200^{\circ} \mathrm{C}(\mathrm{d}): 1-\mathrm{SiC} / \mathrm{Si}, 2-\mathrm{Si}, 3$ - difference spectrum (the spectrum 1 - the spectrum 2 ).

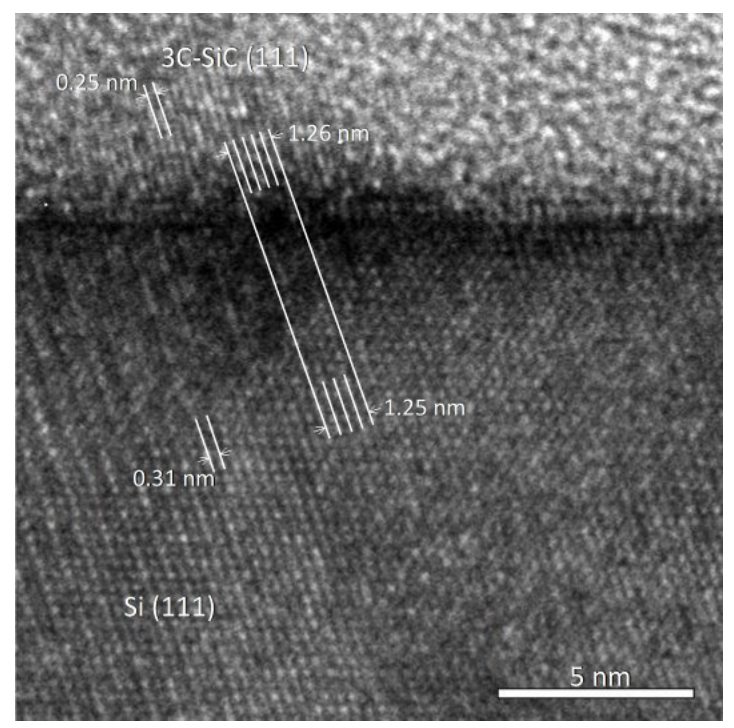

Fig. 4. Cross section TEM image of a $\mathrm{SiC}$ nuclei on a $\mathrm{Si}$ surface.

Figure 6 shows cross section images and TED of SiC films formed on $\mathrm{Si}$ at $1200^{\circ} \mathrm{C}$. For preparing these films, PI films containing 121 layers were used. As can be seen in figure 6, the thickness of the $\mathrm{SiC}$ film is $35 \mathrm{~nm}$ on $\mathrm{Si}(111)$, and $30 \mathrm{~nm}$ on $\mathrm{Si}(100)$.

The $\mathrm{SiC}$ film grown on $\mathrm{Si}(111)$ has a $3 \mathrm{C}-\mathrm{SiC}$ structure with a small presence of a hexagonal phase. Only 3C-SiC films were formed on $\mathrm{Si}(100)$ substrate. It was shown that the $\mathrm{SiC}$ film on $\mathrm{Si}(100)$ consist of two layers. The

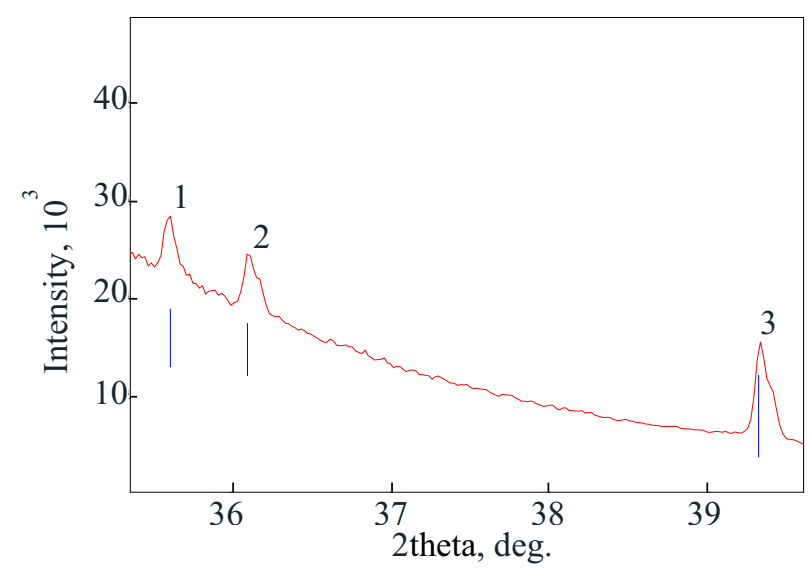

Fig. 5. XRD spectrum of the films after annealing at $1000^{\circ} \mathrm{C}$.
Table 1. The characteristics of XRD spectrum.

\begin{tabular}{|c|c|c|c|c|}
\hline N & $\begin{array}{c}\text { 2theta } \\
\text { (deg.) }\end{array}$ & $\begin{array}{c}\text { d } \\
\text { (ang.) }\end{array}$ & $\begin{array}{c}\text { FWHM } \\
\text { (deg.) }\end{array}$ & $\begin{array}{c}\text { Phase } \\
\text { name }\end{array}$ \\
\hline 1 & 35.619 & 2.518 & 0.060 & $\begin{array}{c}\text { 3C-SiC } \\
\text { or } \\
\text { H-SiC }\end{array}$ \\
\hline 2 & 36.100 & 2.486 & 0.080 & 8H-SiC \\
\hline 3 & 39.308 & 2.290 & $\mathbf{0 . 0 8 0}$ & unknown \\
\hline
\end{tabular}

lower layer $(10 \mathrm{~nm})$ has crystalline structure and the upper layer $(20 \mathrm{~nm})$ is polycrystalline.

The surface morphology of $\mathrm{SiC}$ films was examined by SEM. Figure $7(\mathrm{a}, \mathrm{b})$ shows the presence of faced voids at the $\mathrm{SiC} / \mathrm{Si}$ interface. Most of the voids are closed by $\mathrm{SiC}$ film. It was observed that the shape of voids depends on the symmetry of the substrate surface. The facets of voids are parallel to the lowest surface energy faces, i.e. $\{111\}$ planes (figure 8). Thus, it is approximately square in shape on $\mathrm{Si}(100)$ and triangular on Si (111) substrates. The formation of the voids at the $\mathrm{SiC} / \mathrm{Si}$ interface is caused by the diffusion of the $\mathrm{Si}$ atoms from the Si substrate.

\section{Conclusion}

In the present work we demonstrate an easy strategy to produce high quality single crystal $\mathrm{SiC}$ films on $\mathrm{Si}$ through carbonization of polyimide Langmuir-Blodgett films. To the best of our knowledge, this is the first report of the growth of single crystal $\mathrm{SiC}$ hetero-epitaxial film on $\mathrm{Si}$ with thickness of about $30 \mathrm{~nm}$. The $\mathrm{SiC}\{111\}$ lattice planes are well aligned with those of the $\mathrm{Si}$ substrate. Moreover, every fourth Si plane is aligned with every fifth plane in $3 \mathrm{C}$-SiC(111) structure at the $\mathrm{SiC} / \mathrm{Si}$ interface. It was shown that the $\mathrm{SiC}$ films $(30-35 \mathrm{~nm})$, obtained at $1100^{\circ} \mathrm{C}$ and $1200^{\circ} \mathrm{C}$, are able to close the voids in Si substrate. The size of these voids can reach 10 $\mu \mathrm{m}$. 

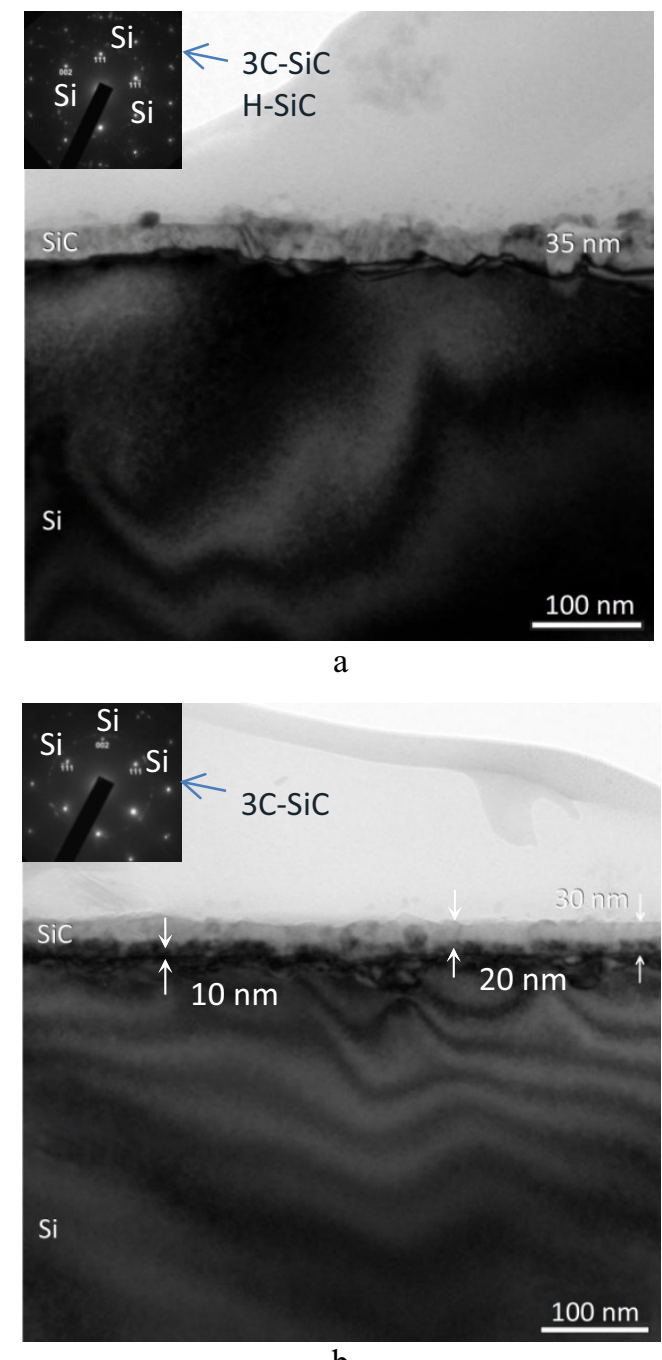

b

Fig. 6. Cross section images and TED of $\mathrm{SiC}$ films formed on $\mathrm{Si}$ at $1200^{\circ} \mathrm{C}$ : a) The $\mathrm{SiC}$ film $(35 \mathrm{~nm})$ on $\mathrm{Si}(111)$ substrate has a $3 \mathrm{C}-\mathrm{SiC}$ structure with a small presence of a hexagonal phase; b) The SiC film on $\mathrm{Si}(100)$ substrate consist of two layers, the lower layer $(10 \mathrm{~nm})$ has $3 \mathrm{C}-\mathrm{SiC}$ structure, and the upper layer $(20 \mathrm{~nm})$ is polycrystalline.

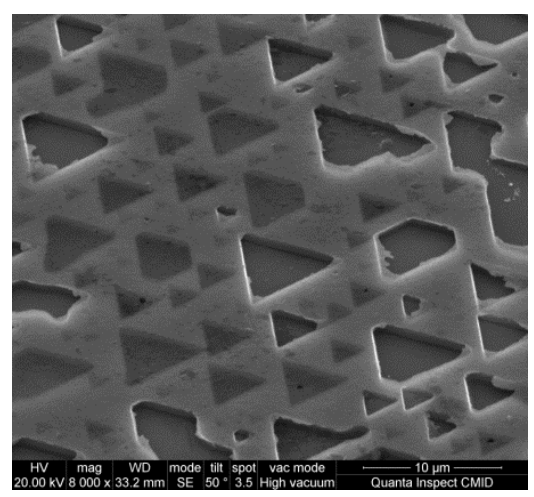

a

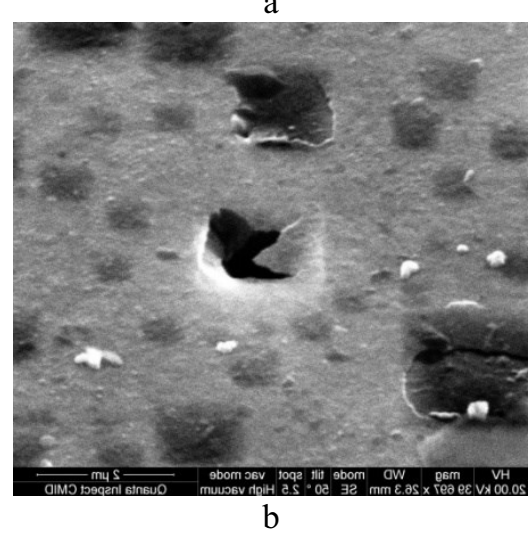

Fig. 7. SEM images of the SiC films covering the voids in $\mathrm{Si}$ (111) (a) and $\mathrm{Si}(100)$ substrates (b). The SiC films on the surface of $\mathrm{Si}$ substrate and the $\mathrm{SiC}$ films covering the voids have the different contrast. The broken $\mathrm{SiC}$ films are also observed.

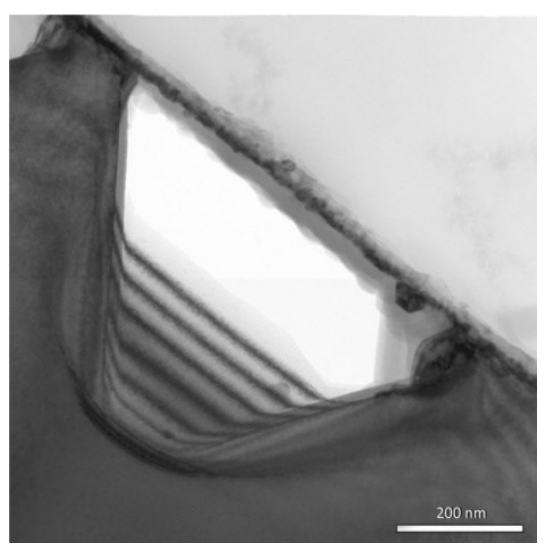

Fig. 8. Cross section TEM of $\mathrm{SiC}$ film with thickness $30 \mathrm{~nm}$, covering a pyramidal void in $\operatorname{Si}(100)$ substrate.

4. A. Severino, R.Anzalone, M.Camarda, N. Piluso, F. La Via. Materials Science Forum. V.711, P.2730 (2012)

5. S. I. Goloudina, V. V. Luchinin, V. M. Pasyuta, V.V Klechkovskaya, Yu. G. Baklagina, V.V. Rozanov, M.F. Panov, V.P. Sklizkova, V.V. Kudryavtsev. Crystallography Reports. P 468-476. 54(3) (2009) 